\title{
Carboxyethylgermanium sesquioxide (Ge-132) treatment during in vitro culture protects fertilized porcine embryos against oxidative stress induced apoptosis
}

\author{
Eunhye KIM ${ }^{1,2)}$, Seon-Ung HWANG ${ }^{1,2)}$, Junchul David YOON1, 2), Eui-Bae JEUNG ${ }^{3)}$, \\ Eunsong LEE$^{4)}$, Dae Young KIM ${ }^{5}$ ) and Sang-Hwan HYUN1, 2) \\ 1) Laboratory of Veterinary Embryology and Biotechnology, Veterinary Medical Center and College of Veterinary Medicine, \\ Chungbuk National University, Cheongju 28644, Republic of Korea \\ 2) Institute of Stem Cell \& Regenerative Medicine (ISCRM), Chungbuk National University, Cheongju 28644, \\ Republic of Korea \\ 3) Laboratory of Veterinary Biochemistry and Molecular Biology, Veterinary Medical Center and College of Veterinary \\ Medicine, Chungbuk National University, Cheongju 28644, Republic of Korea \\ 4) Laboratory of Theriogenology, College of Veterinary Medicine, Kangwon National University, Kangwon 24341, \\ Republic of Korea \\ ${ }^{5)}$ Department of Life Science, College of BioNano Technology, Gachon University, Incheon 13120, Republic of Korea
}

\begin{abstract}
Compared with the in vivo environment, porcine in vitro embryo-culture systems are suboptimal, as they induce oxidative stress via the accumulation of reactive oxygen species (ROS). High ROS levels during early embryonic development cause negative effects, such as apoptosis. In this study, we examined the effects of the antioxidant carboxyethylgermanium sesquioxide (Ge-132) during in vitro culture (IVC) on embryonic development in porcine in vitro fertilization (IVF) embryos. Zygotes were treated with different concentrations of Ge-132 (0, 100, 200 and $400 \mu \mathrm{g} / \mathrm{ml})$. All of the Ge-132 treatment groups displayed greater total cell numbers after IVC (98.1, 98.5 and 103.4, respectively) compared with the control group (73.9). The $200 \mu \mathrm{g} / \mathrm{ml} \mathrm{Ge}-132$ treatment group exhibited significantly increased intracellular GSH levels compared with the control group, whereas the ROS generation levels decreased in Ge-132 dose-dependent manner $(\mathrm{P}<0.05)$. The mRNA expression levels of the KEAP1 gene and proapoptotic genes $B A X$ and $C A S P A S E 3$ were lower in the Ge-132 treated blastocysts compared with the control group $(\mathrm{P}<0.05)$. The percentages of apoptotic and necrotic cells in the Ge-132 treated embryos on day $2(48$ h) were significantly lower than the untreated embryos ( $9.1 \mathrm{vs} .17 .1 \%$ and $0 \mathrm{vs} .2 .7 \%$, respectively). In the day 7 blastocysts, the percentages of apoptotic cells in $200 \mu \mathrm{g} / \mathrm{ml} \mathrm{Ge}-132$ treated group were lower compared to controls (1.6 vs. 2.5\%). More KEAP1 protein was found to be localized in cytoplasm of the $200 \mu \mathrm{g} / \mathrm{ml} \mathrm{Ge}-132$ treated blastocysts, whereas KEAP1 protein was predominantly nuclei in the control blastocysts. These results indicate that the developmental competence of embryos cultured under Ge-132 treatment may be associated with KEAP1 signaling cascades involved in oxidative stress and apoptosis during porcine preimplantation embryo development.
\end{abstract}

Key words: Apoptosis, Ge-132, In vitro culture (IVC) porcine embryos, Oxidative stress

(J. Reprod. Dev. 63: 581-590, 2017)

M any attempts have been made over the past decade to improve the in vitro fertilization (IVF) and in vitro culture (IVC) technology for mammalian embryo production. Despite significant improvements, embryos produced in vitro still differ from embryos produced in vivo because various factors for the generation of embryos are different for in vitro versus in vivo production including oxygen tension, $\mathrm{pH}$, processing and interaction with sperm cells and media to

Received: February 22, 2017

Accepted: September 24, 2017

Published online in J-STAGE: October 6, 2017

(C)2017 by the Society for Reproduction and Development

Correspondence: S-H Hyun (e-mail: shhyun@cbu.ac.kr) and DY Kim (e-mail: davekim@gachon.ac.kr)

This is an open-access article distributed under the terms of the Creative Commons Attribution Non-Commercial No Derivatives (by-nc-nd) License. (CC-BY-NC-ND 4.0: https://creativecommons.org/licenses/by-nc-nd/4.0/) which embryos are exposed [1-3]. One of the environmental factors that could contribute to this difference may be oxidative stress [4]. The level of oxidative stress has been reported to be detrimental to the fate of cells in the embryo toward proliferation, apoptosis or necrosis [5]. Early apoptotic death of embryos due to oxidative stress is still a commonly observed feature of porcine in vitro embryo-culture systems. The fragmentation in porcine embryos also thought to be related to this oxidative stress-induced apoptosis [6]. Today, low oxygen tension (5\%) is applied to the embryo culture system to mimic the oviductal and uterine environment (2-8\%). Previous studies have shown the beneficial effects of low oxygen tension on porcine embryo development compared with atmospheric oxygen $(20 \%)$ $[7,8]$. However, it was not sufficient to simply adjust the oxygen concentration for optimization of porcine embryo development.

Reactive oxygen species (ROS) originate both from the environment and from within the embryos as by-products of the energy metabolism 
pathways [9]. Under in vivo conditions, there are multiple antioxidant systems in porcine embryos, and its environment as preimplantation porcine embryos traverse the female reproductive tract and develop from the zygote to the blastocyst stage [4]. Embryos seem to be protected from ROS damage by the oxygen scavengers present in oviductal fluids. For example, conversion of superoxide anions into $\mathrm{H}_{2} \mathrm{O}_{2}$ or its removal by the activities of catalase in the cytosol and mitochondria of embryos. An imbalance between the level of intracellular ROS and the ROS scavenging capability of embryos, through antioxidants mechanisms, can lead to a state of oxidative stress. In vitro culture conditions and exogenous compounds can enhance the production of ROS and decrease antioxidant defenses by embryos [6]. Several exogenous antioxidants, such as vitamins [10], resveratrol [11], anthocyanin [12], and melatonin [13], have been added to porcine IVC medium to reduce oxidative stress in preimplantation embryos. However, there are still needs to development efficient repair systems for ROS-induced embryo damage.

Carboxyethylgermanium sesquioxide (Ge-132) is the most common water-soluble organic germanium compound which is represented by formula, $\left(\left(\mathrm{HOOCCH}_{2} \mathrm{CH}_{2} \mathrm{Ge}\right)_{2} \mathrm{O}_{3}\right)_{n}$. The Ge-132 is hydrolysis product of trihalogenogermane with well-known acrylic compounds, acrylic acid or its alkyl ester [14]. The Ge-132 has been reported to exhibit broad spectrum of biological activities including antioxidative, anti-tumor, anti-inflammatory, cardiovascular activities with low toxicity [15-17]. Especially, the anti-oxidative function of Ge-132 can be explained by the presence of the chemical structure of $\mathrm{Ge}-\mathrm{C}$ bond which make electron transfer between $\mathrm{Ge}$ and free radicals relatively easy and then scavenge free radicals and reduce oxidative damage $[18,19]$. Recently, to improve the synergetic effect for radicals scavenging, it was used as a component of synthesized antioxidant complex with other promising pharmacologically active agents [20-22]. Therefore, Ge-132 has a potential to cause synergistic effects with other antioxidants known to play antioxidant roles in the development of porcine embryo [10-13].

Our previous study has shown the anti-oxidative effect of Ge-132 treatment during in vitro maturation (IVM) on porcine oocytes by upregulating anti-oxidative related genes and downregulating proapoptotic-associated genes and improved the developmental potential of parthenogenetic and IVF porcine embryos [23]. However, the effect of Ge-132 treatment during preimplantation embryo development has not been investigated until now. Thus, the objective of this study was to examine the effect of Ge-132 treatment on porcine preimplantation IVF embryos during IVC. To this end, we observed embryo cleavage, blastocyst formation, intracellular levels of glutathione (GSH), and ROS, apoptotic index, mRNA (POU5F1, $C D X 2, N R F 2, K E A P 1, B A X$, and CASPASE3) expression and protein (KEAP1 and BCL2) expression in porcine IVF embryos and derivation of putative embryonic stem cells (ESCs) from porcine IVF embryos.

\section{Materials and Methods}

\section{Chemicals}

Unless otherwise indicated, all chemicals and reagents used in the present study were purchased from Sigma-Aldrich (St. Louis, MO, USA).
Oocyte collection and in vitro maturation

Ovaries of prepubertal gilts were collected at a local abattoir and transported to the laboratory within $2 \mathrm{~h}$ in a $0.9 \%(\mathrm{wt} / \mathrm{vol})$ $\mathrm{NaCl}$ solution supplemented with $100 \mathrm{IU} / 1$ penicillin $\mathrm{G}$ and 100 $\mathrm{mg} / \mathrm{ml}$ streptomycin sulfate at 32 to $35^{\circ} \mathrm{C}$. The cumulus oocyte complexes (COCs) in the ovaries were aspirated from 3- to 6-mm diameter superficial follicles using an 18-gauge needle attached to a 10-ml disposable syringe and allowed to settle in $15-\mathrm{ml}$ conical tubes at $37^{\circ} \mathrm{C}$ for $5 \mathrm{~min}$. The supernatant was discarded, and the precipitate was resuspended in HEPES-buffered Tyrode's medium (TLH) containing $0.05 \%$ (wt/vol) polyvinyl alcohol (TLH-PVA). Next, the precipitate was examined using a stereomicroscope to recover the COCs. Only COCs with $\geq 3$ uniform layers of compact cumulus cells and homogenous cytoplasm were selected and washed three times in TLH-PVA. Approximately 60 COCs were placed into each well of a four-well Nunc dish (Nunc, Roskilde, Denmark) containing $500 \mu$ of culture medium (TCM199; Invitrogen, Carlsbad, CA, USA) supplemented with $0.6 \mathrm{mM}$ cysteine, $0.91 \mathrm{mM}$ sodium pyruvate, $10 \mathrm{ng} / \mathrm{ml}$ epidermal growth factor, $75 \mu \mathrm{g} / \mathrm{ml}$ kanamycin, $1 \mu \mathrm{g} / \mathrm{ml}$ insulin, $10 \%$ (vol/vol) porcine follicular fluid, $10 \mathrm{IU} / \mathrm{ml}$ equine chronic gonadotropin (eCG), and $10 \mathrm{IU} / \mathrm{ml}$ human chorionic gonadotropin (Intervet, Boxmeer, Netherlands). The selected COCs were incubated at $39^{\circ} \mathrm{C}$ with $5 \% \mathrm{CO}_{2}$ in a humidified chamber for IVM. After 21 to $22 \mathrm{~h}$ of maturation with hormones, the COCs were washed twice in fresh hormone-free IVM medium and then cultured in hormone-free IVM medium for an additional 21 to $22 \mathrm{~h}$.

\section{In vitro fertilization and culture}

For in vitro fertilization (IVF), the COCs $42-44 \mathrm{~h}$ after IVM were denuded by gently pipetting with $0.1 \%$ hyaluronidase and washed three times in TLH-PVA. Groups of 15 oocytes at the metaphase II stage selected under a stereomicroscope according to the presence of the first polar body were randomly placed in $40 \mu \mathrm{l}$ droplets of modified Tris-buffered medium (mTBM) in a $35 \times 10 \mathrm{~mm}$ Petri dish (Falcon; Becton Dickinson Labware, Franklin Lakes, NJ, USA) covered with pre-warmed mineral oil. Next, commercial liquid semen supplied weekly from the Veterinary Service Laboratory (Department of Livestock Research, Yong-in city, Gyeonggi-do, Republic of Korea) was always stored at $17^{\circ} \mathrm{C}$ for 5 days before use. The semen sample was washed twice with Dulbecco's phosphate buffered saline (DPBS; Invitrogen) supplemented with $0.1 \%$ BSA (Fraction V) via centrifugation at $2000 \mathrm{~g}$ for $2 \mathrm{~min}$. After washing, the sperm pellet was resuspended in $\mathrm{mTBM}$ [24], which had been pre-equilibrated for $18 \mathrm{~h}$ at $39^{\circ} \mathrm{C}$ in $5 \% \mathrm{CO}_{2}$. After appropriate dilution, $5 \mu \mathrm{l}$ of the sperm suspension was added to a $40 \mu \mathrm{l}$ drop of fertilization medium $(\mathrm{mTBM})$ to set the final sperm concentration at $1 \times 10^{6} \mathrm{sperm} / \mathrm{ml}$. Just before fertilization, sperm motility was assessed, and more than $80 \%$ motile sperm were used in every experiment. To use stored liquid semen, a modified two-step culture system [25] was applied. The oocytes were co-incubated with the sperm for $20 \mathrm{~min}$ at $39^{\circ} \mathrm{C}$ in a humidified atmosphere of $5 \% \mathrm{CO}_{2}$ and $95 \%$ air. After $20 \mathrm{~min}$ of co-incubation with the sperm, the loosely attached sperm cells were removed from the zona pellucida $(\mathrm{ZP})$ via gentle pipetting. Next, the oocytes were washed three times in $\mathrm{mTBM}$ and incubated in $\mathrm{mTBM}$ without sperm for 5 to $6 \mathrm{~h}$ at $39^{\circ} \mathrm{C}$ in a humidified atmosphere of $5 \% \mathrm{CO}_{2}$ and $95 \%$ air. Thereafter, the gametes were washed three 
times with embryo culture medium and cultured in $25 \mu 1$ microdrops (10 gametes/drop) of porcine zygote medium 3 (PZM3) [26] with pre-warmed mineral oil. The embryos with cultured drops were incubated at $39^{\circ} \mathrm{C}$ for $168 \mathrm{~h}$ under a humidified atmosphere of $5 \%$ $\mathrm{O}_{2}, 5 \% \mathrm{CO}_{2}$, and $90 \% \mathrm{~N}_{2}$. For all experiments, the culture media were renewed at $48 \mathrm{~h}$ (day 2 ) and $96 \mathrm{~h}$ (day 4 ) after post insemination $(0 \mathrm{~h}=$ beginning of IVF $)$.

\section{Embryo evaluation and total cell count of blastocysts}

The day of IVF was considered day 0 . The embryos were evaluated for cleavage using a stereomicroscope (Olympus SZ51, Tokyo, Japan) on day 2 (48 h). Evenly cleaved embryos were classified into three groups ( 2 to 3,4 to 5 , and 6 to 8 cells). Blastocyst formation was assessed on day 7 (168 h) after IVF, and blastocysts were classified according to the degree of expansion and hatching status [27] as follows: early blastocyst (small blastocyst with a blastocoel equal to or less than half of the embryo volume), expanded blastocyst (a large blastocyst with a blastocoel greater than half of the embryo volume or a blastocyst with a blastocoel completely filling the embryo), and hatched blastocyst (hatching or already hatched blastocyst). The percentage of early, expanded and hatched blastocysts were calculated based on total presumptive zygotes in the culture drop. To quantify the total cell number of blastocysts at day 7, the blastocysts were collected and washed in $1 \%$ (wt/vol) PBS-BSA and stained with 5 $\mu \mathrm{g} / \mathrm{ml}$ Hoechst-33342 (bisbenzimide) for $5 \mathrm{~min}$. After final wash in PBS-BSA, the embryos were fixed briefly in $4 \%$ paraformaldehyde in PBS. Next, the blastocysts were mounted on glass slides in a drop of $100 \%$ glycerol, covered gently with a cover slip, and observed using a fluorescence microscope (Nikon, Tokyo, Japan) at $\times 400$ magnification and manually counted the total cell number of blastocysts. The experiment was repeated five times. All of the blastocysts from three of five repeats were stained for quantification of the cell number, and among them, only the embryos consisting of less than 32 cells were excluded.

\section{Measurement of intracellular GSH and ROS levels}

To determine the effect of Ge-132 treatment on cellular antioxidant potentials during early developmental stages, the 4- to 5- cell stage embryos derived from the IVC medium supplemented with $0,100,200,400 \mu \mathrm{g} / \mathrm{ml} \mathrm{Ge}-132$ were sampled $48 \mathrm{~h}$ after sperm insemination for measurement of intracellular GSH and ROS levels. The GSH and ROS level assessment was performed as previously described [12, 28-30]. Briefly, 2',7'-dichlorodihydrofluorescein diacetate (H2DCFDA; Invitrogen) and 4-chloromethyl-6.8-difluoro7-hydroxycoumarin (CellTracker Blue; CMF2HC; Invitrogen) were used to detect intracellular ROS levels (green fluorescence) and GSH levels (blue fluorescence), respectively. The H2DCFDA is a cell-permeant indicator that becomes fluorescent when oxidized by a variety of ROS. Also, the CMF2HC was used as GSH probe because it contains a chloromethyl group that reacts with thiols, probably in a glutathione S-transferase-mediated reaction, since this has been shown to occur in vitro [30]. In this study, ten embryos from each treatment group were incubated (in the dark) for $30 \mathrm{~min}$ in TLH-PVA supplemented with $10 \mu \mathrm{M}$ H2DCFDA and $10 \mu \mathrm{M}$ CellTracker Blue. After incubation, the embryos were washed with DPBS (Invitrogen) containing $0.1 \%(\mathrm{wt} / \mathrm{vol})$ polyvinyl alcohol (PVA), placed into $10 \mu \mathrm{l}$ droplets, and fluorescence was evaluated using an epifluorescence microscope (TE300; Nikon) with UV filters (460 nm for ROS and $370 \mathrm{~nm}$ for GSH). These fluorescent images were saved as graphic files in TIFF format. The fluorescence intensity of the embryos was analyzed using ImageJ software (Version 1.41; National Institutes of Health, Bethesda, MD, USA) and normalized to control embryos.

Gene expression analysis via quantitative real-time polymerase chain reaction ( $R T-P C R$ )

For the gene expression study, 15 expanded IVF blastocysts per group (control, 100, 200, and $400 \mu \mathrm{g} / \mathrm{ml}$ of Ge-132) were separately sampled using a stereomicroscope. All samples were stored at $-80^{\circ} \mathrm{C}$ until analyzed. The expression levels of POU5F1, CDX2, NRF2, $K E A P 1, B A X$, and CASPASE3 mRNA in the IVF blastocysts were analyzed via quantitative RT-PCR. Total RNA was extracted using TRIzol reagent (Invitrogen) according to the manufacturer's protocol, and the total RNA concentration was determined by measuring the absorbance at $260 \mathrm{~nm}$. First-strand complementary DNA (cDNA) was prepared by subjecting $1 \mu \mathrm{g}$ of total RNA to reverse transcription using Moloney-murine leukemia virus reverse transcriptase (Invitrogen) and random primers (9-mers; TaKaRa Bio, Otsu, Shiga, Japan). To determine the conditions for the logarithmic-phase PCR amplification of target mRNA, $1 \mu \mathrm{g}$ aliquots were amplified using differing numbers of cycles. The housekeeping gene $G A P D H$ was PCR amplified to rule out the possibility of RNA degradation and to control for the variation in mRNA concentrations in the reverse transcription reaction. A linear relationship between the PCR product band visibility and the number of amplification cycles was observed for the target mRNAs. GAPDH and the target genes were quantified for 40 cycles. The cDNA was amplified in a $20 \mu \mathrm{PCR}$ reaction containing $1 \mathrm{U}$ Taq polymerase (Intron Bio Technologies, Seongnam, Korea), $2 \mathrm{mM}$ deoxyribonucleoside triphosphates mix, and $10 \mathrm{pM}$ of each gene-specific primer. The quantitative RT-PCR was performed on MX3000P machine (Stratagene-Agilent Technologies, Waldbronn, Germany) with $1 \mu \mathrm{l}$ cDNA template added to $10 \mu \mathrm{l} 2 \mathrm{X}$ SYBR Premix Ex Taq (TaKaRa Bio) containing specific primers at a concentration of $10 \mathrm{pM}$ each. The reactions were carried out for 40 cycles, and the cycling parameters were as follows: denaturation at $95^{\circ} \mathrm{C}$ for 30 $\mathrm{s}$, annealing at $55^{\circ} \mathrm{C}$ for $30 \mathrm{sec}$, and extension at $72^{\circ} \mathrm{C}$ for $30 \mathrm{sec}$. All oligonucleotide primer sequences are presented in Table 2. The fluorescence intensity was measured at the end of the extension phase of each cycle. The threshold value for the fluorescence intensity of all samples was set manually. The reaction cycle at which the PCR products exceeded this fluorescence intensity threshold was deemed the threshold cycle $(\mathrm{Ct})$ in the exponential phase of the PCR amplification. The expression of each target gene was quantified relative to that of the internal control gene $(G A P D H)$. The relative quantification was based on a comparison of $\mathrm{Cts}$ at constant fluorescence intensity. The amount of transcript present was inversely related to the observed $\mathrm{Ct}$ and, for every twofold dilution in the amount of transcript, the $\mathrm{Ct}$ was expected to increase by one. The relative expression (R) was

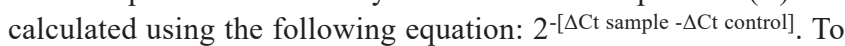
determine a normalized arbitrary value for each gene, every obtained value was normalized to that of GAPDH. The experiments were repeated at least three times. 
Table 1. Primers used for gene expression analysis

\begin{tabular}{|c|c|c|c|}
\hline mRNA & Primer sequences & $\begin{array}{l}\text { Product size } \\
\text { (base pairs) }\end{array}$ & $\begin{array}{l}\text { Gene Bank accession } \\
\text { number or reference }\end{array}$ \\
\hline \multirow[t]{2}{*}{ GAPDH } & F: 5'-GTCGGTTGTGGATCTGACCT-3' & 207 & NM_001206359 \\
\hline & R: 3'-TTGACGAAGTGGTCGTTGAG-5' & & \\
\hline \multirow[t]{2}{*}{ POU5F1 } & F: 5'-GCGGACAAGTATCGAGAACC-3' & 200 & NM_001113060 \\
\hline & R: 3'-CCTCAAAATCCTCTCGTTGC-5' & & \\
\hline \multirow[t]{2}{*}{$C D X 2$} & F: 5'-GGAACCTGTGCGAGTGGATG-3' & 168 & CK_458871 \\
\hline & R: 3'-GCTCGGCCTTTCTCCGAATG-5' & & \\
\hline \multirow[t]{2}{*}{$N R F 2$} & F: 5'-CCCATTCACAAAAGACAAACATTC-3' & 71 & {$[60]$} \\
\hline & R: 3'-GCTTTTGCCCTTAGCTCATCTC-5' & & \\
\hline \multirow[t]{2}{*}{$K E A P 1$} & F: 5'-AGCTGGGATGCCTCAGTGTT-3' & 100 & NM001114671.1 \\
\hline & R: 3'-AGGCAAGTTCTCCCAGACATTC-3' & & \\
\hline \multirow[t]{2}{*}{$B A X$} & F: 5'-TGCCTCAGGATGCATCTACC-3' & 199 & XM_003127290 \\
\hline & R: 3'-AAGTAGAAAAGCGCGACCAC-5' & & \\
\hline \multirow[t]{2}{*}{ CASPASE3 } & F: 5'-CGTGCTTCTAAGCCATGGTG-3' & 186 & NM_214131 \\
\hline & R: 3'-GTCCCACTGTCCGTCTCAAT-5' & & \\
\hline
\end{tabular}

Table 2. Effect of Ge-132 treatment during IVC on embryonic development after in vitro fertilization (IVF)

\begin{tabular}{ccccc}
\hline \multirow{2}{*}{$\begin{array}{c}\text { Ge-132 concentration } \\
(\mu \mathrm{g} / \mathrm{ml})\end{array}$} & $\begin{array}{c}\text { No. of embryos } \\
\text { cultured }\end{array}$ & \multicolumn{2}{c}{ No. of embryos developed to $\left(\%{ }^{\mathrm{a}}\right)$} & \multirow{2}{*}{$\begin{array}{c}\text { Total cell numbers in } \\
\text { Blastocyst }\left(\mathrm{N}^{\mathrm{b}}\right)\end{array}$} \\
\hline 0 (Control) & 234 & $144(61.6 \pm 0.7)^{\mathrm{c}, \mathrm{d}}$ & $62(26.5 \pm 0.5)^{\mathrm{c}}$ & $73.9 \pm 6.7(23)^{\mathrm{c}}$ \\
100 & 233 & $157(67.4 \pm 1.3)^{\mathrm{d}}$ & $76(32.6 \pm 2.1)^{\mathrm{d}}$ & $98.1 \pm 7.7(24)^{\mathrm{d}}$ \\
200 & 234 & $157(67.1 \pm 2.5)^{\mathrm{d}}$ & $72(30.8 \pm 2.0)^{\mathrm{c}, \mathrm{d}}$ & $98.5 \pm 9.3(23)^{\mathrm{d}}$ \\
400 & 233 & $142(60.9 \pm 2.3)^{\mathrm{c}}$ & $61(26.1 \pm 4.2)^{\mathrm{c}}$ & $103.4 \pm 9.3(23)^{\mathrm{d}}$ \\
\hline
\end{tabular}

${ }^{a}$ Percentage of total cultured oocytes. ${ }^{b}$ Number of examined blastocysts. ${ }^{c}, d$ Values with different superscripts within a column differ significantly $(\mathrm{P}<0.05)$. The experiment was repeated five times. The data represent the mean $\pm \mathrm{SEM}$.

\section{Apoptosis (Annexin $V$ and propidium iodide assay)}

To examine the effect of Ge-132 treatment on apoptosis during early developmental stages, early porcine embryos on day 2 (48 h) or day $7(168 \mathrm{~h})$ cultured with or without $200 \mu \mathrm{g} / \mathrm{ml} \mathrm{Ge}-132$ containing medium were stained using an Annexin V/ propidium iodide (PI) assay (eBioscience, San Diego, CA, USA) for apoptosis analysis, following the manufacturer's instructions. Briefly, embryos were rinsed in $1 \mathrm{X}$ binding buffer and incubated with annexin $\mathrm{V}$ (Fluorescein isothiocyanate-labeled) for $10 \mathrm{~min}$ at room temperature. Embryos were incubated with the PI solution for another $30 \mathrm{sec}$ at room temperature, then washed in $1 \%(\mathrm{wt} / \mathrm{vol})$ PBS-BSA and stained with $5 \mu \mathrm{g} / \mathrm{ml}$ Hoechst-33342 (bisbenzimide) for $5 \mathrm{~min}$, and mounted on slides for evaluation under epifluorescence microscope (TE300; Nikon). Embryos were classified in three groups reflecting the apoptotic criteria in oocytes proposed by Anguita [31], representing (1) viable non-apoptotic embryos, with intact Hoechst positive nuclei and no annexin staining; (2) early apoptotic embryos with intact Hoechst positive nuclei and a homogeneous annexin positive signal in the membrane; and (3) late apoptotic or necrotic embryos which showed PI positive red nuclei, which is indicative for membrane damage. In this last group, there were occasionally signs of annexin staining in the membrane. The apoptotic index (percentage of apoptotic or necrotic cells) was obtained as the ratio of the number of apoptotic or necrotic cells relative to counted total cells following cell counting in the well-labeled areas, as determined by scanning at low magnification. The experiment was repeated three times. The total number of evaluated embryos used per group is presented in Table 3 .

\section{Protein expression analysis via immunofluorescence staining}

To observe the protein expression during Ge-132 treatment and determine the key signal pathways, porcine embryos were sampled from control (no Ge-132) and $200 \mu \mathrm{g} / \mathrm{ml} \mathrm{Ge}-132$ treatment groups at day 7 after IVF. They were fixed with $4 \%$ paraformaldehyde for $40 \mathrm{~min}$, then permeabilized with $1 \%$ Triton X-100 for $30 \mathrm{~min}$. After incubation in Image-iTTM FX Signal Enhancer (I36933, Invitrogen) for $30 \mathrm{~min}$, the embryos were further blocked with $1 \%$ bovine serum albumin (BSA, A9418) in PBS for $1 \mathrm{~h}$. They were then incubated with a primary antibody overnight at $4^{\circ} \mathrm{C}$. The primary antibodies used were KEAP1 (ABS97, Millipore, Temecula, CA, 1:200) and BCL2 (SC23960, Santa Cruz, Dallas, TX, 1:200). After completely washing and secondary blocking, they were further incubated with the appropriate secondary antibodies. After the nuclei were stained with $10 \mu \mathrm{g} / \mathrm{ml}$ Hoechst 33342 (B2261), the embryos were mounted with anti-fade reagent (S36937, Invitrogen) and observed under laserscanning confocal microscope (LSM700, Carl Zeiss, Oberkochen, Germany) and ZEN 2009 Light Edition software (Carl Zeiss). 
Table 3. Effect of Ge-132 treatment to the IVC medium on the apoptotic index of Day 2 porcine embryos

\begin{tabular}{|c|c|c|c|c|c|c|}
\hline \multirow{2}{*}{ Group } & \multicolumn{3}{|c|}{ No. of embryos * } & \multicolumn{3}{|c|}{ No. of cells (apoptotic index **, \%) } \\
\hline & evaluated & Early apoptosis & Late apoptosis / Necrosis & evaluated & Early apoptosis & Late apoptosis / Necrosis \\
\hline Control & 26 & 14 & 3 & 146 & $27(17.1 \pm 3.3)^{\mathrm{a}}$ & $3(2.7 \pm 1.5)^{\mathrm{a}}$ \\
\hline Ge-132 & 30 & 14 & 0 & 173 & $16(9.1 \pm 2.2)^{b}$ & $0(0.0 \pm 0.0)^{b}$ \\
\hline
\end{tabular}

* Porcine embryos cultured with or without $200 \mu \mathrm{g} / \mathrm{ml}$ Ge-132 containing in vitro culture (IVC) medium. ** Apoptotic index, percentage of apoptotic (Annexin V-positivie /PI-negative) or necrotic (Annexin V-positivie /PI-positive) cells in the embryos of each group. ${ }^{\text {a, b }}$ Values with different superscripts within a column differ significantly $(\mathrm{P}<0.05)$. The experiment was repeated three times. The data represent the mean \pm SEM.

\section{Experimental design}

In experiment 1 , the effect of treatments with various concentrations $(0,100,200$ and $400 \mu \mathrm{g} / \mathrm{ml})$ of Ge-132 for the whole culture period (days 0 to 7) during IVC on the developmental competence of IVF embryos was examined to determine the optimal concentration. The experiment was repeated five times. The total number of oocytes used per treatment group is presented in Table 1. In experiment 2 , the effect of Ge-132 treatment $(0,100,200$ and $400 \mu \mathrm{g} / \mathrm{ml})$ during IVC on intracellular levels of GSH and ROS was investigated to determine cellular antioxidant potentials. This experiment was repeated three times (total GSH samples, $\mathrm{N}=150$; total ROS samples, $\mathrm{N}=156$ ). In experiment 3, we investigated the effects of Ge-132 treatment $(0,100,200$ and $400 \mu \mathrm{g} / \mathrm{ml})$ on the mRNA expression of POU5F1, $C D X 2, N R F 2, K E A P 1, B A X$, and CASPASE3. The experiments were repeated at least three times. Based on the results including developmental competence, intracellular GSH and ROS levels and gene expression, optimal Ge-132 concentration $(200 \mu \mathrm{g} / \mathrm{ml})$ for the in vitro development of porcine embryos was selected for the following apoptosis-related experiments. Experiment 4 and 5 was conducted to examine the effect of $200 \mu \mathrm{g} / \mathrm{ml} \mathrm{Ge}-132$ treatment during IVC on apoptotic index and apoptosis-related protein expression of KEAP1 and BCL2 in blastocysts using Annexin V/ PI assay and immunofluorescence analysis, respectively. The experiment was repeated three times.

\section{Statistical analysis}

The statistical analyses were performed using SPSS 17.0 (SPSS, Chicago, IL, USA). A one-way analysis of variance followed by Duncan's multiple range tests with least significant difference was conducted to assess percentage data (e.g., cleavage, blastocyst formation, number of nuclei, cleavage pattern, blastocyst stage pattern, relative level or GSH and ROS, mRNA expression and derivation efficiency of ESCs); a Student's $t$-test was conducted to assess the apoptotic index. All results are expressed as the mean \pm SEM. $\mathrm{P}$ values $<0.05$ were considered statistically significant, unless otherwise stated.

\section{Results}

Experiment 1: Developmental competence of porcine IVF embryos in chemically defined medium supplemented with different concentrations of Ge-132 during in vitro culture (IVC)

At day 2 after IVF, there were significantly higher number of
4- to 5 -cell embryos in the 100 - and $200-\mu \mathrm{g} / \mathrm{ml} \mathrm{Ge-132 \text {groups }}$ than in the control groups. In addition, there were significantly less $(\mathrm{P}<0.05)$ fragmented embryos in the $100-$ and $200-\mu \mathrm{g} / \mathrm{ml}$ Ge-132 treatment groups than in the control group (Fig. 1A). The embryonic developmental competence to the blastocyst stage after IVF was significantly $(\mathrm{P}<0.05)$ higher in the $100 \mu \mathrm{g} / \mathrm{ml} \mathrm{Ge}-132$ group (32.6\%) than in the control group (26.5\%) (Table 2). All of the Ge-132 treatment groups displayed greater total cell numbers after IVC (98.1, 98.5 and 103.4, respectively) than the control group (73.9). As shown in Fig 1B, hatched blastocyst formation on day 7 was significantly higher in the $100-$ and $200-\mu \mathrm{g} / \mathrm{ml} \mathrm{Ge}-132$ groups than the other groups.

Experiment 2: Effect of Ge-132 during in vitro culture (IVC) on intracellular levels of GSH and ROS in the IVF embryos

To assess anti-oxidative effect of Ge-132, an analysis of intracellular GSH and ROS levels in the IVF embryos derived from the culture medium supplemented with Ge-132 was performed (Fig. 2). The $200-\mu \mathrm{g} / \mathrm{ml} \mathrm{Ge}-132$ treatment group exhibited significantly increased $(\mathrm{P}<0.05)$ intracellular GSH levels compared with the control group. The ROS generation significantly decreased $(\mathrm{P}<0.05)$ as the Ge-132 concentrations increased.

\section{Experiment 3: Effect of Ge-132 treatment during in vitro culture (IVC) on gene expression of IVF embryos}

To examine the effect of Ge-132 on the expression of inner cell mass (ICM) and trophectoderm (TE)-related genes, anti-oxidative-related and apoptosis-related genes, we evaluated the mRNA expression levels of POU FF1, CDX2, NRF2, KEAP1, BAX, and CASPASE 3 in the blastocysts of each group (Fig. 3). $C D X 2$ transcript levels were significantly lower in the blastocysts treated with all concentrations of Ge-132 $(100,200$, and $400 \mu \mathrm{g} / \mathrm{ml})$, although no difference was observed in the POU5F1 transcript levels compared with the control $(0 \mu \mathrm{g} / \mathrm{ml} \mathrm{Ge}-132)$. The mRNA transcript levels of KEAP1 significantly decreased when Ge-132 concentrations increased ( $\mathrm{P}$ $<0.05$ ) and expressed significantly lower in the $400 \mu \mathrm{g} / \mathrm{ml} \mathrm{Ge}-132$ group than control embryos $(\mathrm{P}<0.05)$. However, there were no significant differences in $N R F 2$ transcript levels among the groups under the same conditions. Furthermore, we also found that the 200 $\mu \mathrm{g} / \mathrm{ml} \mathrm{Ge}$-132-treated embryos exhibited significantly lower mRNA expression levels of the pro-apoptotic gene $B A X$ and CASPASE 3 compared with the control group $(\mathrm{P}<0.05)$. 

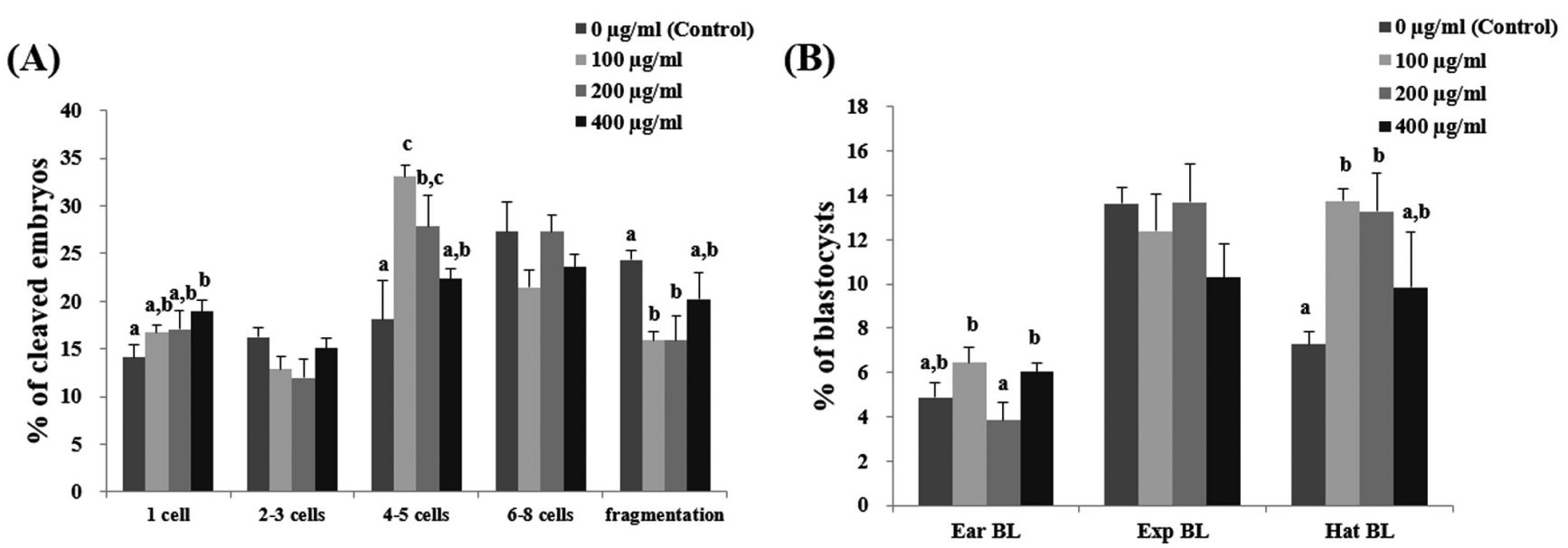

Fig. 1. Effect of various concentrations of Ge-132 treatment during in vitro culture (IVC) on the cleavage pattern of in vitro fertilization (IVF) embryos at day 2 (A) and the percentage of IVF embryos that developed to the blastocyst stage at day 7 (B). For each end point, bars with different letters $(\mathrm{a}-\mathrm{c})$ are significantly $(\mathrm{P}<0.05)$ different for different concentrations of Ge-132. EarBL, early blastocyst; ExpBL, expanded blastocyst; HatBL, hatched blastocyst. The experiment was replicated five times.

\section{(A) Control}
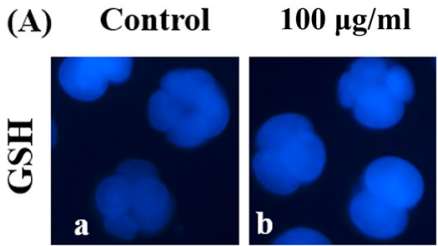

$200 \mu \mathrm{g} / \mathrm{ml}$
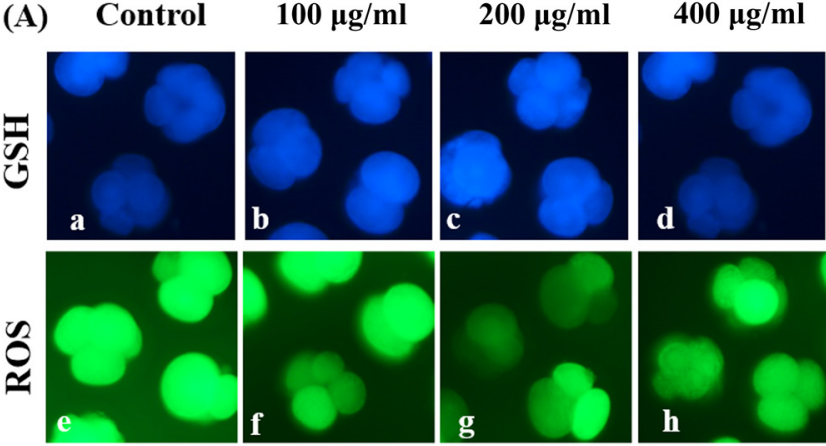

(B)

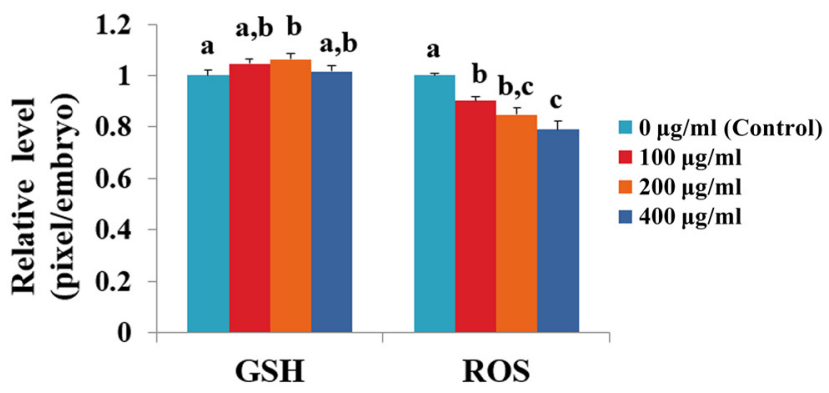

Fig. 2. Epifluorescentphotomicrographic images of in vitro cultured porcine embryos. (A) Embryos were stained with CellTracker Blue (a-d) and 2', 7'-dichlorodihydrofluorescein diacetate (H2DCFDA) (e-h) to detect the intracellular levels of glutathione (GSH) and reactive oxygen species (ROS), respectively. Porcine embryos on day 2 at the 4- to 5-cell stages derived from the in vitro culture (IVC) medium supplemented with $0 \mu \mathrm{g} / \mathrm{ml} \mathrm{Ge}-132$ (a and e), $100 \mu \mathrm{g} / \mathrm{ml} \mathrm{Ge}-132$ (b and f), $200 \mu \mathrm{g} / \mathrm{ml} \mathrm{Ge}-132$ (c and g) and $400 \mu \mathrm{g} / \mathrm{ml} \mathrm{Ge}-132$ (d and h). (B) The relative levels of intracellular GSH and ROS in in vitro cultured porcine embryos among the four groups $(0 \mu \mathrm{g} / \mathrm{ml}, 100 \mu \mathrm{g} / \mathrm{ml}, 200 \mu \mathrm{g} / \mathrm{ml}$ and 400 $\mu \mathrm{g} / \mathrm{ml} \mathrm{Ge}-132)$. Within each group end point (GSH and ROS), the bars with different letters $(\mathrm{a}-\mathrm{c})$ are significantly $(\mathrm{P}<0.05)$ different. The experiment was replicated three times.
Experiment 4: Effect of Ge-132 during in vitro culture (IVC) on the morphology and apoptosis rates in the IVF embryos

Because ROS, which can induce the cell death [32], and mRNA expression levels of the pro-apoptotic genes were significantly reduced in Ge-132 treatment group, we hypothesized that the Ge132 supplementation may impact apoptosis during in vitro culture of porcine embryos. To ascertain whether the Ge-132 is able to prevent apoptosis, we next evaluated apoptotic index in early (day 2) embryos (Table 3). The Annexin V / PI staining showed that the early and late apoptotic index in the Ge-132 treated embryos were significantly lower than the untreated embryos $(9.1 v s .17 .1 \%$ and 0 vs. 2.7\%, respectively). Also, as shown in Table 4, staining revealed significantly lower percentage of Annexin V-positive/PI-negative (apoptotic) cells in the day 7 blastocysts treated with $200 \mu \mathrm{g} / \mathrm{ml}$ Ge-132, compared to controls (1.6 vs. $2.5 \%$ ).

\section{Experiment 5: Effect of Ge-132 treatment during in vitro culture (IVC) on protein expression of IVF embryos}

To further assess the involvement of the KEAP1 and BCL2 in Ge-132 treatment, we conducted immunofluorescence assay in blastocysts at day 7 (Fig. 4). The immunofluorescence staining showed that more KEAP1 protein was found to be localized in cytoplasm of the $200 \mu \mathrm{g} / \mathrm{ml} \mathrm{Ge}-132$ treated blastocysts, whereas KEAP1 protein was predominantly nuclei in the control blastocysts in agreement with the mRNA expression pattern in blastocysts (Fig. 3). Also, significantly high $\mathrm{BCL} 2$ protein levels $(\mathrm{P}<0.05)$ could be detected in Ge-132 treated blastocysts compared to control blastocysts (Fig. 4).

\section{Discussion}

This study of porcine embryo development revealed that appropriate concentrations of Ge-132 (1) decreased the percentage of fragmented embryos at day 2 and improved the blastocyst formation rate and mean number of cells in the blastocyst after fertilization in vitro, (2) increased intracellular GSH levels but decreased ROS levels in 4 to 


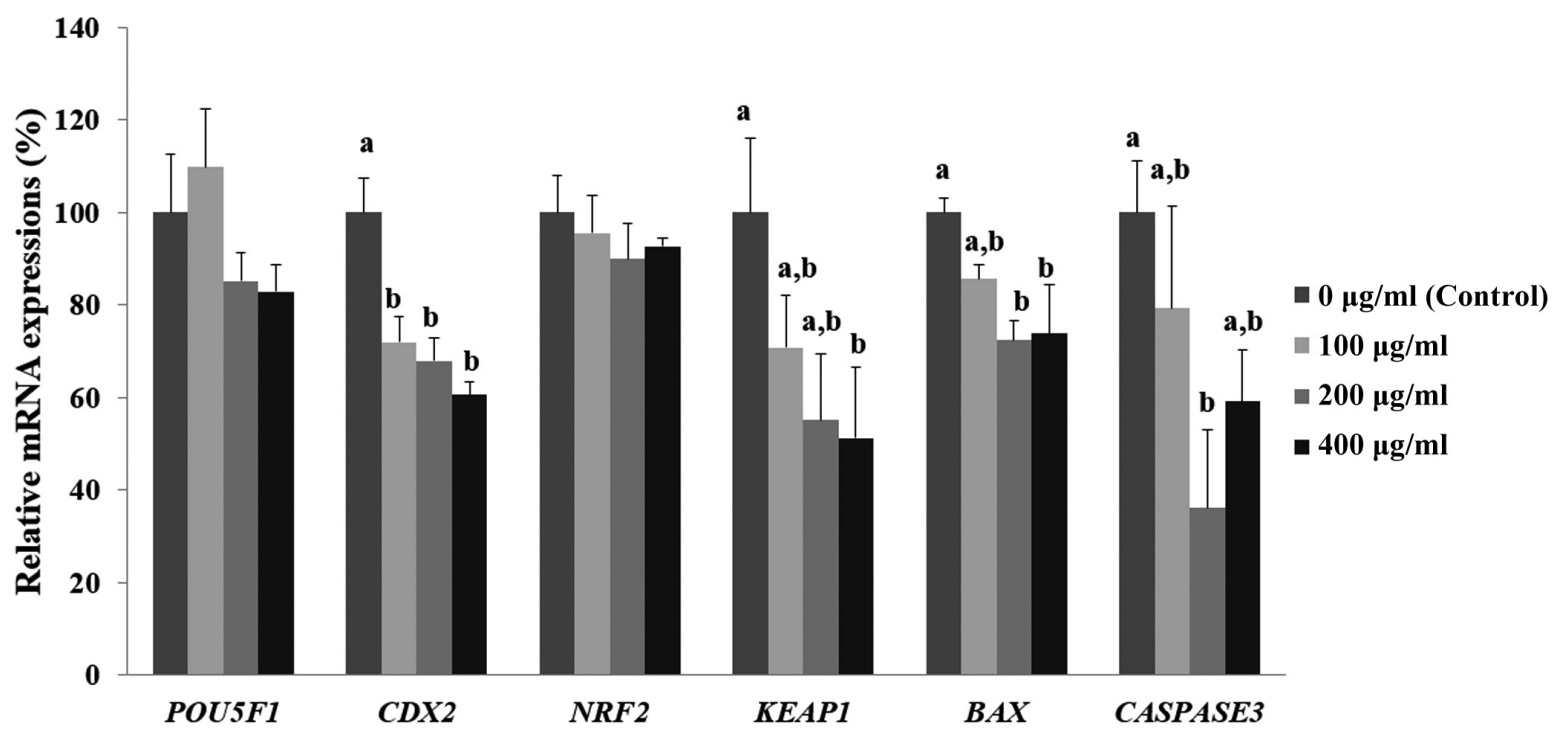

Fig. 3. mRNA expression levels (Mean $\pm \mathrm{SEM}$ ) of POU5F1, CDX2, NRF2, KEAP1, BAX, and CASPASE3 in blastocysts treated with Ge-132 during in vitro culture (IVC). Within the same target mRNA, values with different superscript letters $(a$ and $b)$ are significantly $(P<0.05)$ different. The experiment was replicated at least three times.

Table 4. Effect of Ge-132 treatment to the IVC medium on the apoptotic index of Day 7 porcine blastocysts

\begin{tabular}{cccc}
\hline \multirow{2}{*}{ Group } & No. of blastocysts* evaluated & \multicolumn{2}{c}{ No. of blastomeres (apoptotic index **, \%) } \\
\cline { 3 - 4 } & 23 & evaluated & apoptosis \\
\hline Control & 23 & 1699 & $44(2.5 \pm 0.3)^{\mathrm{a}}$ \\
Ge-132 & 2266 & $35(1.6 \pm 0.3)^{\mathrm{b}}$ \\
\hline
\end{tabular}

* Porcine blastocysts cultured with or without $200 \mu \mathrm{g} / \mathrm{ml} \mathrm{Ge}-132$ containing in vitro culture (IVC) medium.

** Apoptotic index, percentage of Annexin V-positivie /PI-negative cells in the blastocysts of each group.

a, b Values with different superscripts within a column differ significantly $(\mathrm{P}<0.05)$. The experiment was repeated three times. The data represent the mean \pm SEM.

(A)
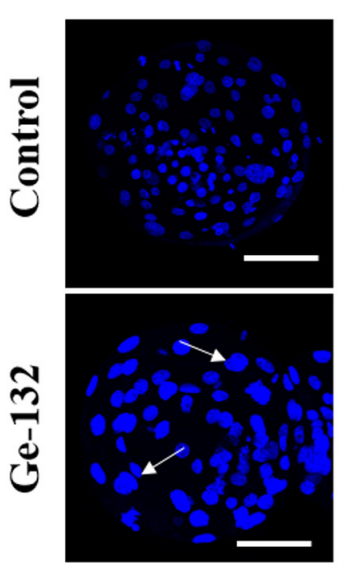

KEAP1
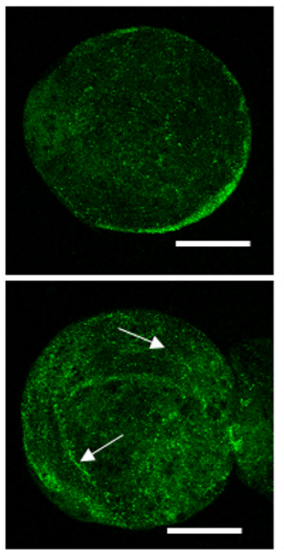

BCL2
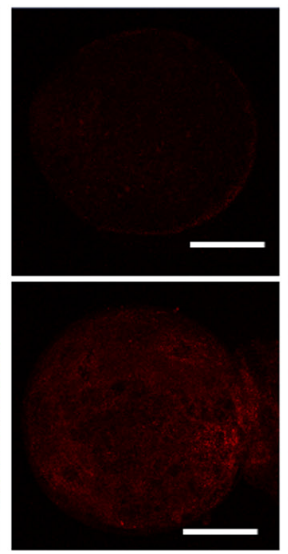

Merge
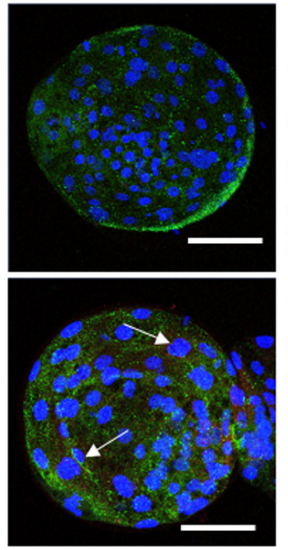

(B)

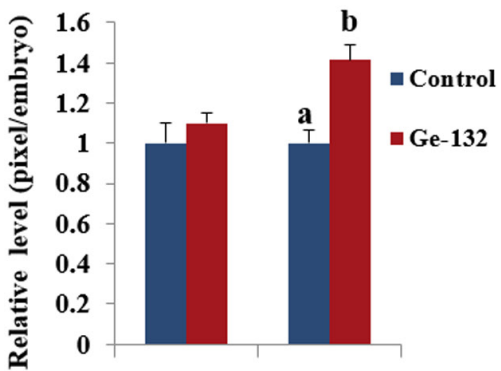

KEAP1 BCL2

Fig. 4. Effect of Ge-132 on the protein expression of KEAP1 and BCL2 in blastocysts treated with Ge-132 during in vitro culture (IVC). (A) Green fluorescence signals reveal KEAP1 protein localization, while red fluorescence signals showed BCL2 protein expression. The cells were counterstained with Hoechst (blue fluorescence) to visualize nuclear morphology. The white arrow indicates the absent of KEAP1 in nuclei (localization in cytosol). Each image shown is representative of at least 14 random fields observed. Indicated scale bars signify $100 \mu \mathrm{m}$ distance. (B) The intensity of KEAP1 and BCL2 was quantitated by densitometric analysis and is shown in the histogram. The data is represented as the mean \pm SD from three independent experiments. Within each group end point (KEAP1 and BCL2), the bars with different letters (a, b) are significantly $(\mathrm{P}<0.05)$ different. 
5-cell stage embryos, (3) decreased the expression of KEAP1 and the pro-apoptotic cascade genes such as $B A X$ and $C A S P A S E 3$ and increased the expression of BCL2 in blastocysts, and (4) decreased the apoptosis in the IVF embryos.

The concept that a controlled redox system is essential for normal embryogenesis is further supported by the fact that dysregulation of the redox equilibrium severely interferes with embryo development [33]. Particularly, embryos under in vitro conditions are more sensitive to oxidative damage and inevitably exposed to oxidative stress generated by ROS, which act as second messengers by regulating key transcription factors associated with the oxidative process [34]. Furthermore, during this oxidative process, the GSH status in the rodent or porcine embryos is vital, considering that GSH is a major ROS-scavenging factor of the damaged cells and is related to the cell proliferation during embryonic event [35-37]. The reduced intracellular level of ROS and increased GSH level in the Ge-132-treated embryos on day 2 may indicate that the uncontrolled equilibrium of pro- and anti-oxidative processes under in vitro system, which can retard embryo development, may be regulated by Ge-132 supplementation.

Our previous study demonstrated that Ge-132 during IVM system has the capacity to act as ROS scavengers associated with nuclear factor (erythroid-derived 2) like 2 (NRF2)-regulated antioxidant pathway and protects porcine oocytes from damage caused by oxidative stress [23]. The NRF2 is the key transcription factor that regulates many antioxidant genes in mammalian cell and is a wellknown substrate of kelch-like ECH-associated protein 1 (KEAP1), which is an inhibitor of NRF2 [38]. Therefore, we speculated that Ge-132 supplementation during entire IVC system can facilitate the defense mechanism, particularly NRF2-dependent induction of GSH, against ROS and ameliorate the oxidative stress caused during early embryonic development, such as in the IVM system. However, we found that although KEAP1 mRNA expression levels were lower in the Ge-132 treated embryos on day 7, there were no significant changes in NRF2 mRNA expression levels compared with the control group. Using cues from other articles [39, 40], BCL2 has been reported as another substrate of KEAP1 instead of NRF2. The apoptotic pathways rely on a complex balance in the function of the BCL2 family [41], with anti-apoptotic (BCL-2, BCL-XL) and pro-apoptotic (BAX, BAK) members. The preimplantation embryos have a variety of the expression levels in the BCL2 family [42]. It was thought that KEAP1 under the normal in vitro condition of embryos facilitates Cul3-Rb1-mediated ubiquitination and degradation of BCL2 followed by the accumulation of BAX and the subsequent release of cytochrome $\mathrm{C}$ from mitochondrial membranes and activation of caspase 3, leading to apoptosis. In the present study, the more KEAP1 protein localization in cytoplasm and increased expression of BCL2 with Ge-132 treatment, directly indicating a coordinated inactivation of the KEAP1-regulated apoptotic pathway, which led to the regulation of a variety of apoptotic genes, such as the BCL2 family. Our data suggests the activities of the KEAP1-mediated mechanisms under Ge-132 treatment during the development of in vitro embryos. Under Ge-132 treatment, the down-regulation of KEAP1 induces the dissociation of BCL2, causing an increase in BCL2:BAX heterodimers, which is followed by a decrease in BAX, and subsequently reduced apoptosis and enhanced cell survival in in vitro embryos. These results support and extend recent studies showing that Ge-132 may simultaneously stimulate protection against oxidative stress and following apoptotic mechanisms that may be harmful to the development of embryos.

Cell death has been traditionally thought to be divided into two types, apoptosis and necrosis, which represent programmed cell death and accidental cell death, respectively $[43,44]$. In many cells, including embryos, apoptosis performs the functions of regulating cell number and eliminating inappropriate or damaged cells, similar to necrosis $[45,46]$. However, it should be strictly controlled to prevent inappropriate loss of normal cells. This regulation may be more aberrant in in vitro production embryos, due in part to the suboptimal culture conditions compared with the in vivo derived embryos. Furthermore, the cytoplasmic fragmentation of mammalian embryos is closely associated with both apoptosis and necrosis during preimplantation development $[47,48]$. To provide direct evidence that Ge-132 plays an important role in apoptosis and fragmentation during embryo development, we observed the cleavage pattern and performed Annexin V/PI assay to evaluate apoptotic index in day 2 and day 7 embryos. The results support that Ge-132 treatment may reduce excessive apoptosis or necrosis, which may result in impaired cellular growth and embryo fragments in accordance with cleavage pattern data in this study. Although very little is known regarding the mechanism of Ge-132 related to apoptosis, according to a recent study, Ge-132 can interact with physiological cis-diol compounds, such as adenosine triphosphate (ATP), and form complexes [49]. Intracellular ATP levels appear to be a factor that determines cell death fate by apoptosis and necrosis [50]. Most of the fragmented blastomeres indicate depletion of ATP, which is one of the characteristics of necrotic cells that exhibit mitochondrial deficiency [51]. However, a higher proportion of organogermanium 3-(trihydroxygermyl) propanoic acid (THGPA), which is a hydrolysate of Ge-132, may be present in the extracellular space compared with in the intracellular fluid because it may not be readily incorporated into intercellular compartments. Therefore, the ATP chelating effect of THGPA may be involved not in intracellular ATP but in extracellular ATP (eATP). This suggests that a similar underlying mechanism that chelate formation between Ge-132 and eATP may reduce apoptosis under excessive ATP supplying conditions during in vitro development of embryos may be a possible explanation for the anti-apoptotic effect of Ge-132 [52, 53]. One caveat that should be taken into consideration is a possible reduction with time in the intracellular ATP of the embryos. To answer whether Ge-132 treatment is involved in intracellular ATP will require further investigation.

Down-regulation of $C D X 2$ leads to asymmetric divisions, thereby contributing to the ICM, whereas up-regulation of $C D X 2$ promotes symmetric divisions and consequently contribution to the TE [45]. Interestingly, although the mRNA expression level of $C D X 2$ was decreased and there were no significant changes in the mRNA levels of POU 5F1 in response to any of the treatments used here, all of the Ge-132 treated groups exhibited increased total cell numbers in the blastocysts. These results suggested that treatment of Ge-132 during porcine IVC might affect ICM and TE quality. Evidence from another study from mouse embryos also indicated that the total cell number remained unchanged upon $C D X 2$ depletion [54]. In addition, the apoptotic cells were increased in a $C D X 2$-deficient blastocyst. However, the results of this study support the anti-apoptotic 
effect of Ge-132. Thus, we postulate that Ge-132 overcomes the apoptotic impact caused by the down-regulated $C D X 2$ activating KEAP1-BCL2 system. There are many grading systems to evaluate blastocysts including the degree of expansion of the cavity and whether or not it has started to "hatch" or breaking of the ZP. In vivo, a blastocyst hatches on day 6 or 7 after fertilization. Failure to "hatch" has been attributed to zona hardening and suboptimal culture conditions [55]. In this study, 100- and $200-\mu \mathrm{g} / \mathrm{ml} \mathrm{Ge}-132$ not only decreased the fragmentation rate on day 2 , but also improved the percentage of hatched blastocysts on day 7 compared to the control group. Based on these results, $100-$ and $200-\mu \mathrm{g} / \mathrm{ml} \mathrm{Ge}-132$ might be optimal concentrations for development of porcine embryos. Also, the derivation efficiency of ESC might be another tool to evaluate blastocysts indirectly [56]. Some reports have shown that reducing oxidant stress increased the success of establishing new mouse and porcine ESC lines [57, 58]. Although further experiments need to be conducted, the putative porcine ESC lines were derived from 100- and $200-\mu \mathrm{g} / \mathrm{ml} \mathrm{Ge}-132$ treatment group and showed a similar derivation process with primed ESCs, such as previously reported porcine ESC lines [59] as shown in Supplementary Table 1 and Supplementary Fig. 1 (online only). These newly derived porcine ESC lines may be used as sources for further rigorous analyses on the role of Ge-132 during the specification of cell fate and differentiation.

In summary, our results suggest that Ge-132 supplementation during development of porcine early in vitro-fertilized embryos is highly efficient, highlighting the ability of Ge-132 to activate the apoptosis defense mechanism, which is primarily driven by the KEAP1-associated anti-apoptotic pathway. To our knowledge, the present study demonstrates for the first time a critical role for KEAP1-dependent BCL2-induced signaling in porcine embryo development against oxidative stress. Overall, these findings provide a new and comprehensive information and in-depth insight into the molecular mechanisms of Ge-132 that confers anti-oxidative and anti-apoptotic protection during in vitro development model.

\section{Acknowledgments}

This work was supported, in part, by a grant from the "the Next-Generation BioGreen 21 Program (Project No. PJ011288, PJ011077)" Rural Development Administration, the "National Research Foundation of Korea Grant funded by the Korean Government (NRF-2016R1D1A1B03933191, NRF2017R1A2B4002546)", "Korea Institute of Planning and Evaluation for Technology in Food, Agriculture, Forestry and Fisheries (IPET) through Advanced Production Technology Development Program, funded by Ministry of Agriculture, Food and Rural Affairs (MAFRA) (Grant number: 115103-02)", The Global Research and Development Center (GRDC) Program through the National Research Foundation of Korea (NRF) funded by the Ministry of Education, Science and Technology (2017K1A4A3014959) and Business for Cooperative R\&D between Industry, Academy, and Research Institute funded Korea Small and Medium Business Administration in 2017 (Grants No. 2017020681010101), Republic of Korea.

\section{References}

1. Macháty Z, Day BN, Prather RS. Development of early porcine embryos in vitro and in vivo. Biol Reprod 1998; 59: 451-455. [Medline] [CrossRef]

2. Agarwal A, Allamaneni SS, Nallella KP, George AT, Mascha E. Correlation of reactive oxygen species levels with the fertilization rate after in vitro fertilization: a qualified metaanalysis. Fertil Steril 2005; 84: 228-231. [Medline] [CrossRef]

3. Gadea J. Sperm factors related to in vitro and in vivo porcine fertility. Theriogenology 2005; 63: 431-444. [Medline] [CrossRef]

4. Guérin P, EI Mouatassim S, Ménézo Y. Oxidative stress and protection against reactive oxygen species in the pre-implantation embryo and its surroundings. Hum Reprod Update 2001; 7: 175-189. [Medline] [CrossRef]

5. Dennery PA. Effects of oxidative stress on embryonic development. Birth Defects Res $C$ Embryo Today 2007; 81: 155-162. [Medline] [CrossRef]

6. Kitagawa Y, Suzuki K, Yoneda A, Watanabe T. Effects of oxygen concentration and antioxidants on the in vitro developmental ability, production of reactive oxygen species (ROS), and DNA fragmentation in porcine embryos. Theriogenology 2004; 62: 1186-1197. [Medline] [CrossRef]

7. Berthelot $\mathbf{F}$, Terqui M. Effects of oxygen, $\mathrm{CO}_{2} / \mathrm{pH}$ and medium on the in vitro development of individually cultured porcine one- and two-cell embryos. Reprod Nutr Dev 1996; 36: 241-251. [Medline] [CrossRef]

8. Booth PJ, Holm P, Callesen H. The effect of oxygen tension on porcine embryonic development is dependent on embryo type. Theriogenology 2005; 63: 2040-2052. [Medline] [CrossRef]

9. Harvey AJ, Kind KL, Thompson JG. REDOX regulation of early embryo development. Reproduction 2002; 123: 479-486. [Medline] [CrossRef]

10. Jeong YW, Park SW, Hossein MS, Kim S, Kim JH, Lee SH, Kang SK, Lee BC, Hwang WS. Antiapoptotic and embryotrophic effects of $\alpha$-tocopherol and L-ascorbic acid on porcine embryos derived from in vitro fertilization and somatic cell nuclear transfer. Theriogenology 2006; 66: 2104-2112. [Medline] [CrossRef]

11. Lee K, Wang C, Chaille JM, Machaty Z Z. Effect of resveratrol on the development of porcine embryos produced in vitro. J Reprod Dev 2010; 56: 330-335. [Medline] [CrossRef]

12. You J, Kim J, Lim J, Lee $\mathbf{E}$. Anthocyanin stimulates in vitro development of cloned pig embryos by increasing the intracellular glutathione level and inhibiting reactive oxygen species. Theriogenology 2010; 74: 777-785. [Medline] [CrossRef]

13. Rodriguez-Osorio N, Kim IJ, Wang H, Kaya A, Memili E. Melatonin increases cleavage rate of porcine preimplantation embryos in vitro. J Pineal Res 2007; 43: 283-288. [Medline] [CrossRef]

14. Kaplan BJ, Parish WW, Andrus GM, Simpson JSA, Field CJ. Germane facts about germanium sesquioxide: I. Chemistry and anticancer properties. J Altern Complement Med 2004; 10: 337-344. [Medline] [CrossRef]

15. Brutkiewicz RR, Suzuki F. Biological activities and antitumor mechanism of an immunopotentiating organogermanium compound, Ge-132 (review) (review). In Vivo 1987; 1 189-203. [Medline]

16. Prónai L, Arimori S. Decreased plasma superoxide scavenging activity in immunological disorderscarboxyethylgermanium sesquioxide (Ge-132) as a promoter of prednisolone. Biotherapy 1992; 4: 1-8. [Medline] [CrossRef]

17. Yang MK, Kim YG. Protective role of germanium-132 against paraquat-induced oxidative stress in the livers of senescence-accelerated mice. J Toxicol Environ Health A 1999; 58: 289-297. [Medline] [CrossRef]

18. Pi J, Zeng J, Luo J-J, Yang P-H, Cai J-Y. Synthesis and biological evaluation of Germanium(IV)-polyphenol complexes as potential anti-cancer agents. Bioorg Med Chem Lett 2013; 23: 2902-2908. [Medline] [CrossRef]

19. Hiraoka A, Inaba H, Suzuki E, Kasai K, Suzuki H, Shinohara A, Shirao M, Kubo K, Yoshimura Y. In vitro physicochemical properties of neutral aqueous solution systems (water products as drinks) containing hydrogen gas, 2-carboxyethyl germanium sesquioxide, and platinum nanocolloid as additives. J Health Sci 2010; 56: 167-174. [CrossRef]

20. Yamaguchi H, Shimada Y, Takeda T, Nakamura T, Mano N. A novel extraction method based on a reversible chemical conversion for the LC/MS/MS analysis of the stable organic germanium compound Ge-132. Anal Chem 2015; 87: 2042-2047. [Medline] [CrossRef]

21. Li S-P, Xie W-L, Cai H-H, Cai J-Y, Yang P-H. Hydroxyl radical scavenging mechanism of human erythrocytes by quercetin-germanium (IV) complex. Eur J Pharm Sci 2012; 47 28-34. [Medline] [CrossRef]

22. Jiang J, Yao S, Cai H-H, Yang P-H, Cai J. Synthesis and synergetic effects of chrysinorganogermanium (IV) complex as potential anti-oxidant. Bioorg Med Chem Lett 2013; 23: 5727-5732. [Medline] [CrossRef]

23. Kim E, Jeon Y, Kim DY, Lee E, Hyun S-H. Antioxidative effect of carboxyethylgermanium sesquioxide (Ge-132) on IVM of porcine oocytes and subsequent embryonic development after parthenogenetic activation and IVF. Theriogenology 2015; 84: 226-236. 
[Medline] [CrossRef]

24. Abeydeera LR, Day BN. In vitro penetration of pig oocytes in a modified Tris-buffered medium: effect of BSA, caffeine and calcium. Theriogenology 1997; 48: 537-544. [Medline] [CrossRef]

25. Gil MA, Ruiz M, Vazquez JM, Roca J, Day BN, Martinez EA. Effect of short periods of sperm-oocyte coincubation during in vitro fertilization on embryo development in pigs. Theriogenology 2004; 62: 544-552. [Medline] [CrossRef]

26. Yoshioka K, Suzuki C, Tanaka A, Anas IM-K, Iwamura S. Birth of piglets derived from porcine zygotes cultured in a chemically defined medium. Biol Reprod 2002; 66: 112-119. [Medline] [CrossRef]

27. Cheng TC, Huang CC, Huang LS, Chen CI, Lee MS, Liu JY. Evaluation of mouse blastocyst implantation rate by morphology grading. Chin J Physiol 2004; 47: 43-47. [Medline]

28. Nasr-Esfahani MH, Aitken JR, Johnson MH. Hydrogen peroxide levels in mouse oocytes and early cleavage stage embryos developed in vitro or in vivo. Development 1990; 109: 501-507. [Medline]

29. Sakatani M, Suda I, Oki T, Kobayashi S, Kobayashi S, Takahashi M. Effects of purple sweet potato anthocyanins on development and intracellular redox status of bovine preimplantation embryos exposed to heat shock. J Reprod Dev 2007; 53: 605-614. [Medline] [CrossRef]

30. Zhang Y, Olson N, Mao F, Roth B, Haugland R. New fluorescent-probes for long-term tracing of living cells. FASEB J 1992; 6: A1835.

31. Anguita B, Paramio MT, Morató R, Romaguera R, Jiménez-Macedo AR, Mogas T, Izquierdo D. Effect of the apoptosis rate observed in oocytes and cumulus cells on embryo development in prepubertal goats. Anim Reprod Sci 2009; 116: 95-106. [Medline] [CrossRef]

32. Simon H-U, Haj-Yehia A, Levi-Schaffer F. Role of reactive oxygen species (ROS) in apoptosis induction. Apoptosis 2000; 5: 415-418. [Medline] [CrossRef]

33. Ufer C, Wang CC, Borchert A, Heydeck D, Kuhn H. Redox control in mammalian embryo development. Antioxid Redox Signal 2010; 13: 833-875. [Medline] [CrossRef]

34. Agarwal A, Gupta S, Sharma RK. Role of oxidative stress in female reproduction. Reprod Biol Endocrinol 2005; 3: 28. [Medline] [CrossRef]

35. Gardiner CS, Reed DJ. Status of glutathione during oxidant-induced oxidative stress in the preimplantation mouse embryo. Biol Reprod 1994; 51: 1307-1314. [Medline] [CrossRef]

36. Ishibashi M, Akazawa S, Sakamaki H, Matsumoto K, Yamasaki H, Yamaguchi Y, Goto S, Urata Y, Kondo T, Nagataki S. Oxygen-induced embryopathy and the significance of glutathione-dependent antioxidant system in the rat embryo during early organogenesis. Free Radic Biol Med 1997; 22: 447-454. [Medline] [CrossRef]

37. Ozawa M, Nagai T, Fahrudin M, Karja NWK, Kaneko H, Noguchi J, Ohnuma K, Kikuchi K. Addition of glutathione or thioredoxin to culture medium reduces intracellular redox status of porcine IVM/IVF embryos, resulting in improved development to the blastocyst stage. Mol Reprod Dev 2006; 73: 998-1007. [Medline] [CrossRef]

38. Nguyen T, Nioi P, Pickett CB. The Nrf2-antioxidant response element signaling pathway and its activation by oxidative stress. J Biol Chem 2009; 284: 13291-13295. [Medline] [CrossRef]

39. Niture SK, Jaiswal AK. Inhibitor of Nrf2 (INrf2 or Keap1) protein degrades Bcl-xL via phosphoglycerate mutase 5 and controls cellular apoptosis. J Biol Chem 2011; 286: 44542-44556. [Medline] [CrossRef]

40. Tian H, Zhang B, Di J, Jiang G, Chen F, Li H, Li L, Pei D, Zheng J. Keap1: one stone kills three birds Nrf2, IKK $\beta$ and Bcl-2/Bcl-xL. Cancer Lett 2012; 325: 26-34. [Medline] [CrossRef]

41. Gross A, McDonnell JM, Korsmeyer SJ. BCL-2 family members and the mitochondria in apoptosis. Genes Dev 1999; 13: 1899-1911. [Medline] [CrossRef]
42. Betts DH, King WA. Genetic regulation of embryo death and senescence. Theriogenology 2001; 55: 171-191. [Medline] [CrossRef]

43. Zakeri Z, Bursch W, Tenniswood M, Lockshin RA. Cell death: programmed, apoptosis, necrosis, or other? Cell Death Differ 1995; 2: 87-96. [Medline]

44. Edinger AL, Thompson CB. Death by design: apoptosis, necrosis and autophagy. Curr Opin Cell Biol 2004; 16: 663-669. [Medline] [CrossRef]

45. Elmore S. Apoptosis: a review of programmed cell death. Toxicol Pathol 2007; 35: 495-516. [Medline] [CrossRef]

46. Hao Y, Lai L, Mao J, Im GS, Bonk A, Prather RS. Apoptosis and in vitro development of preimplantation porcine embryos derived in vitro or by nuclear transfer. Biol Reprod 2003; 69: 501-507. [Medline] [CrossRef]

47. Chi H-J, Koo J-J, Choi S-Y, Jeong H-J, Roh S-I. Fragmentation of embryos is associated with both necrosis and apoptosis. Fertil Steril 2011; 96: 187-192. [Medline] [CrossRef]

48. Jurisicova A, Varmuza S, Casper RF. Programmed cell death and human embryo fragmentation. Mol Hum Reprod 1996; 2: 93-98. [Medline] [CrossRef]

49. Nakamura T, Shimada Y, Takeda T, Sato K, Akiba M, Fukaya H. Organogermanium compound, Ge-132, forms complexes with adrenaline, ATP and other physiological cisdiol compounds. Future Med Chem 2015; 7: 1233-1246. [Medline] [CrossRef]

50. Eguchi Y, Shimizu S, Tsujimoto Y. Intracellular ATP levels determine cell death fate by apoptosis or necrosis. Cancer Res 1997; 57: 1835-1840. [Medline]

51. Van Blerkom J, Davis P, Alexander S. A microscopic and biochemical study of fragmentation phenotypes in stage-appropriate human embryos. Hum Reprod 2001; 16: 719-729. [Medline] [CrossRef]

52. Wei Q, Zhang Y, Sun L, Jia X, Huai W, Yu C, Wan Z, Han L. High dose of extracellular ATP switched autophagy to apoptosis in anchorage-dependent and anchorage-independent hepatoma cells. Purinergic Signal 2013; 9: 585-598. [Medline] [CrossRef]

53. Zheng LM, Zychlinsky A, Liu C-C, Ojcius DM, Young JD-E. Extracellular ATP as a trigger for apoptosis or programmed cell death. J Cell Biol 1991; 112: 279-288. [Medline] [CrossRef]

54. Wu G, Gentile L, Fuchikami T, Sutter J, Psathaki K, Esteves TC, Araúzo-Bravo MJ, Ortmeier C, Verberk G, Abe K, Schöler HR. Initiation of trophectoderm lineage specification in mouse embryos is independent of Cdx2. Development 2010; 137: 4159-4169. [Medline] [CrossRef]

55. Sathananthan $\mathbf{H}$, Menezes $\mathbf{J}$, Gunasheela $\mathbf{S}$. Mechanics of human blastocyst hatching in vitro. Reprod Biomed Online 2003; 7: 228-234. [Medline] [CrossRef]

56. Wang F, Kong HJ, Kan QC, Liang JY, Zhao F, Bai AH, Li PF, Sun YP. Analysis of blastocyst culture of discarded embryos and its significance for establishing human embryonic stem cell lines. J Cell Biochem 2012; 113: 3835-3842. [Medline] [CrossRef]

57. Wang F, Thirumangalathu S, Loeken MR. Establishment of new mouse embryonic stem cell lines is improved by physiological glucose and oxygen. Cloning Stem Cells 2006; 8: 108-116. [Medline] [CrossRef]

58. Cheong SA, Kim E, Kwak SS, Jeon Y, Hyun SH. Improvement in the blastocyst quality and efficiency of putative embryonic stem cell line derivation from porcine embryos produced in vitro using a novel culturing system. Mol Med Rep 2015; 12: 2140-2148. [Medline] [CrossRef]

59. Kim E, Hwang S-U, Yoo H, Yoon JD, Jeon Y, Kim H, Jeung E-B, Lee C-K, Hyun S-H Putative embryonic stem cells derived from porcine cloned blastocysts using induced pluripotent stem cells as donors. Theriogenology 2016; 85: 601-616. [Medline] [CrossRef]

60. Nannelli A, Rossignolo F, Tolando R, Rossato P, Longo V, Gervasi PG. Effect of $\beta$-naphthoflavone on AhR-regulated genes (CYP1A1, 1A2, 1B1, 2S1, Nrf2, and GST) and antioxidant enzymes in various brain regions of pig. Toxicology 2009; 265: 69-79. [Medline] [CrossRef] 